\title{
EMOTION AND E-LEARNING
}

\author{
Kerry O'Regan \\ Learning and Teaching Development Unit \\ The University of Adelaide \\ South Australia, Australia 5005, \\ Telephone: +61 883034721 \\ Fax: +61 883033553 \\ Email: kerry.oregan@adelaide.edu.au
}

\begin{abstract}
Traditionally, emotion and cognition have been viewed as polar opposites and this view has been incorporated into theories of learning. One reason for this may be a lack of clarity in defining emotion. In fact there are other perspectives on how emotion and cognition, emotion and learning, are related. These considerations emerge with renewed vigor with the move to online education. The author interviewed eleven students studying online. These students identified emotions which were critical to their online learning. Evidence from the literature and from the interviews positions emotion as central and essential to the teaching/ learning process.
\end{abstract}

\section{KEYWORDS}

Learning Effectiveness, Emotion, Student Satisfaction

\section{EMOTION AND COGNITION-THE TRADITIONAL VIEW}

The Western approach to thinking and feeling, cognition and emotion, has been to regard them as polar opposites. Throughout the Western tradition of philosophy, from Plato who regarded emotions as 'irrational urges that needed to be controlled through the use of reason' [1], through Descartes whose attitude seemed to be 'If I am because I think, then I am undone if I feel' [2], and Kant for whom emotion was 'an illness of the mind' [3], there has been a consistent and entrenched belief that emotions are erratic and untrustworthy and that for sanity and civility to prevail, rationality and intellect must function unfettered by the vagaries of emotion. This belief has underpinned much of what goes on in Western society, its influence being felt nowhere more than in the world of teaching and learning.

So it is that learning theories, particularly those concerned with learning at higher levels of education, have largely treated emotion and cognition as occupying separate realms, cognitive processes having prime (or even sole) place in the educational scheme of things [4, 5, 6]. Martin and Briggs [7] almost twenty years ago now, challenged this view. They proposed the integration of the two domains, affective and cognitive, into a more holistic and realistic framework for instructional design. However, this proposal has proved to be rather more problematic and less popular than Martin and Briggs may have envisaged. One of the reasons for the continuing separation of emotion and cognition is the difficulty in defining just what it is we are talking about when we speak of emotion, there being many perspectives and a multitude of definitions $[8,9,10,11]$.

\section{WHAT IS EMOTION?}

Among the various attempts to understand and define emotion, a number of approaches can be identified. Darwin [12] was perhaps the first to systematically identify and categorize a 
comprehensive range of emotions. He considered emotions to represent mechanisms for the adaptation and survival of the individual. And this evolutionary function of emotion is still acknowledged by some contemporary writers in the field of emotion $[13,2,14]$.

Another perspective is to consider emotions in behaviorist terms, seeing them essentially as states elicited by 'the delivery, omission, or termination of rewarding or punishing stimuli' [9]. This approach is based on the principle of a simple pleasure/pain dichotomy, the various possible emotions representing seeking out or avoidance responses of an individual to the relevant positive or negative stimuli [15]. A variation of this view is to focus primarily on emotions as motivators of behavior or 'transformations of dispositions to act' [2]. Within this framework, emotions are seen as instrumental in influencing the choices made by an individual in response to certain stimuli $[10,16]$.

Emotion can also be regarded as some combination (with various emphases and sequences) of physiological, psychological and psychomotor components. James [17] was an early proponent of this general approach, defining emotion in terms of the feeling of the 'bodily expressions' which follow the perception of an 'exciting fact'. Other variations identify 'affective' and 'somatic' dimensions of emotion [18], 'experiential, behavioral and physiological' aspects [13], or 'corporeal' and 'cognitive' dimensions [19].

The above approaches all construct emotion as an essentially individual phenomenon. Emotions, however, can also be viewed in socio-cultural terms, Goleman [20], for example, describing them as things we catch from each other 'as though they were some kind of social virus.' Denzin [8] sees emotions as 'social acts involving interactions with self and interactions with others,' while for Averill [21] an emotion is 'a transitory social role' which exists in both an interpersonal and a sociocultural context.

The most recent developments in the understanding of emotion have been in the field of neurobiology. Rather than considering emotions as either psychological states or social phenomena, here they are studied in terms of their corresponding brain function [10]. Clinical studies of the brain have identified emotion as being associated with complex biological processes in which neurological, biochemical, and sociocultural factors all play a part. Evidence from such studies shows how emotions 'retain a primacy that subtly pervades our mental life...hav[ing] a say on how the rest of the brain and cognition go about their business' [22].

As well as consideration of the purpose and function of emotions there is also the question of just what emotions exist. Darwin [12] identified over thirty different emotions which he categorized into seven groups, clustering similar emotions together. James [17] identified 'coarser' (grief, fear, rage and love) and 'subtler' emotions 'whose organic reverberation is less obvious and strong'. Similar, more recent classification systems include Damasio's [22] 'primary' (happiness, sadness, anger, fear and disgust) and 'secondary' emotions. The latter are 'subtle variations' of the primary ones and include emotions such as euphoria, ecstasy, melancholy and wistfulness. Averill [21] proposed a system of emotional classes or 'paradigms', 'impulsive', 'conflictive' and 'transcendental'. However, some emotion theorists, James and Averill included, consider that there are numerous, and perhaps endless, possibilities of emotions, these being determined to some extent by the socio-cultural context in which they occur [21].

These various constructions of emotion each provide particular insights into what is a complex phenomenon. Experiential knowing of emotion is part of the human condition. However, a clear, agreed upon definition seems to be not easily arrived at. As LeDoux [10 p.23] said "everyone knows what [emotion] is until they are asked to define it." To the question what are emotions, LeDoux responds "there are many answers. Many of them surprisingly unclear and ill-defined" [9]. The picture of emotions that emerges is diverse and multifaceted. This complexity makes the task of 
exploring the relationship between emotion and learning a difficult one. Baulking at that task, however, means limiting our understanding of what is happening in the teaching/learning process.

\section{EMOTION AND COGNITION—OTHER POSSIBILITIES}

While the oppositional relationship between emotion and cognition is deeply entrenched in our philosophical psyche, this is by no means the whole or only story. Different juxtapositions of cognition and emotion are evident in various teaching/learning theory frameworks. Some of these frameworks recognize the importance of emotion but position the affective domain as being somehow separate from, but nevertheless providing a basis for, functioning in the cognitive domain. In the tradition of Bloom's [23] and Krathwohl, Bloom and Masia's [24] taxonomies of cognitive and affective objectives, the existence of these two educationally relevant domains is acknowledged, but they are positioned as being distinct from each other. This underpinning model persists in studies such as McLeod's [25] review of research into emotion and learning in mathematics, which identifies separate cognitive and affective domains. Shelton [26], too, writing of the importance of emotion in learning addresses the need to develop certain 'emotional competencies' before learning can proceed satisfactorily. Similarly, Postle [27] talks of the importance of 'emotional competence' in relation to learning. In his terms, learning can be inhibited by emotional incompetence. He draws on Heron's model of multi-modal learning in which action, conceptual and imaginal learning all depend on the capacity to learn at an emotional level. So, with this approach, emotion is relevant to learning in that it provides a base or substrate out of which healthy cognitive functioning can occur.

Another perspective sees emotion as being associated with cognition in some kind of parallel way. Gardner's [28] theory of multiple intelligences (including intrapersonal and interpersonal intelligences) and Goleman's [20] theory of emotional intelligence both construct emotion as analogous to the more traditional cognitive 'intelligence'. Emotion is somehow like cognition but operating in another, parallel, realm. 'Our emotions have a mind of their own, one which can hold views quite independently of our rational minds' [20]. Within this framework, the Gray-LaViolette [29] ECS (emotional/cognitive structures) theory uses a couple of metaphors (musical tones and woven fabric) to try to express a perceived relationship between emotion and cognition which is perhaps more intertwined than parallel. The ECS model, as with Gardner's and Goleman's theories, acknowledges the existence of emotion in relation to learning, but lacks a clear functional mechanism to connect the two.

So there has been an ongoing, if at times tentative, exploration of the relationship between emotion and cognition. This has led to a growing awareness that, far from being polar opposites, they are in fact inextricably connected. "Cognition is not as logical as it was once thought and emotions are not as illogical" [10]. In particular, the field of neurobiology alluded to earlier, has produced clinical evidence of connections between emotion and certain key cognitive processes. The work of Damasio [22] for example has led him to propose that 'there is a particular region in the human brain where systems concerned with emotion/feeling, attention, and working memory interact so intimately that they constitute the source for the energy of both external action (movement) and internal action (thought animation, reasoning)'. This vital connection between emotion and the cognitive processes of attention, memory and decision-making is being recognized by a range of researchers and practitioners $[4,30,31,19]$. And the practical implications of this are beginning to be felt. Stock [32], for example, found it 'disquieting' that he had spent so much time on developing a purely cognitive model of performance in organizations. He felt compelled by the research to revise his model, coming to acknowledge that 'all sensory input is processed through our emotional center first...before it is sent to be processed in our rational mind'. The centrality of emotion in many cognitive processes is now being acknowledged. They are seen by some as 'mak[ing] possible all creative thought' [33], of being 'ways of disclosing the world for the person' [8], of being 'a sort of biological thermostat [which] activates attention ... which then activates a rich set of problem-solving and response systems' [34], of alerting us to specific kinds of problems [35], of serving as 'the mind's primary 
architect' [33]. In fact, of 'driv[ing] everything' [34].

Despite the historical tradition which discounted the significance of emotion for any serious human endeavor, the 1980s in particular saw a burgeoning of interest in the place of emotion in a whole range of areas. 'Philosophical, anthropological, psychological, and social psychological conceptions of emotion are taking root in the human disciplines' [8]. This interest was reflected in a strand of research into the significance of emotion for learning in the teaching/learning contexts of the time [36, 37]. But teaching and learning occurs now in a wide range of contexts, of particular significance being the incursion of the teaching/learning experience into the online environment. The frontier nature of online teaching and learning provides a stimulus to reconsider educational theory and practice and to question the assumptions underlying these. What is their validity? What is missing?

\section{LEARNING ONLINE}

It has been estimated that around 2 million students are now taking courses online from higher education institutions in the United States [38]. Teaching and learning online brings with it a whole new and largely unknown set of parameters which have to do with every aspect of being and learning in an online environment. Life online is not the same as life in the face to face world. Our very identity becomes something uncertain and ambiguous. 'The Internet is a mask of sorts. It hides the color of our skin, the shape and size of our body, its beauty and its blemishes, our age, our accents, our incomes and our fashion sense' [39]. Teaching and learning online can be, in Mezirow's terms, 'the ultimate disorienting dilemma' [40] where the familiar frameworks and markers of everyday life and learning no longer exist, or at least exist in unfamiliar forms. There has been considerable research into some aspects of this phenomenon, much of it having to do with the comparative effectiveness of different modes of teaching and learning (including, specifically, the online mode).

As Russell's [41] website indicates, hundreds of such studies show there to be no significant difference in students' performance with variation in the mode of teaching and learning. He argues the futility of carrying out such coarse grained research, maintaining that 'individual differences in learning styles dictate that technology will facilitate learning for some, but will probably inhibit learning for others'. Other critiques of research in the area claim that the research focuses on the technology, resource efficiency, policy and pedagogy, with little exploration of the student experience and the implications of that [42]. There has, however, been some research into the student experience, and even into the emotions associated with that experience. Kort, Reilly and Picard [43], for example, are attempting to develop a model of emotion related to various phases of learning. They have identified several axes specifying a range of emotional states and hope eventually to devise a computer-based system whereby both learner and teacher can recognize the student's emotional position in relation to learning.

There have also been studies of online learning in which emotion, while not being the major focus, has at least been acknowledged. Martinez [5] has carried out research into online learning and devised a model of learning orientations which 'recognizes a dominant influence of emotions, intentions and social factors on how individuals learn differently.' Some of the research has identified some of the emotions experienced by students studying online. A study by Schaller and colleagues [44] found that students experienced bewilderment and confusion as they attempted to navigate their way through the required learning site. Wegerif [45] reported that students of the Open University were inhibited by feelings of fear and alienation as they experienced the exposure and the isolation that learning online can entail. $\mathrm{Ng}$ [46] discovered that some students studying online reported considerable anxiety at communicating electronically, realizing that this form of communication required new social and communication skills. Hara and Kling [47] set out specifically to investigate students' distress associated with studying a web based course. In their study, the expected problem of isolation did not emerge as an issue. They did however, identify considerable frustration experienced by students with the technical aspects of leaning online, with interpreting and following instructions and with 
managing the enormous amounts of email they were required to deal with. They questioned the apparently positive results of some surveys into online learning, suggesting that students' private revelations sometimes bore considerable contrast to their public responses in which they may be reluctant to express negative attitudes.

\section{EMOTION AND E-LEARNING}

While the studies cited above have indicated, at least in a peripheral way, that emotion is associated with learning online, there has been little exploration of the extent, nature and significance of this. The growing body of research and scholarship relating to emotion and learning generally indicates the significant part that emotion plays in learning. Models of learning online are still being developed. It is important that the opportunity not be lost to include the emotional dimension in this development, so that the theory and practice of teaching and learning online can be the richer for it and the more authentic. Research, qualitative and quantitative, large-scale and small should be carried out in a range of teaching and learning settings to inform more fully the theory and practice of teaching and learning online.

\section{THE STUDY}

This present study is informed by the author's experience of supporting the learning of students at university. It occurs in the context of an Australian university which is increasingly committed to providing courses online and attempts to explore the lived experience of some of those for whom this institutional commitment is an educational reality. It is also informed by the author's experiential and theoretical interest in the connection between emotion and learning and sits beside those studies which have begun to identify the emotions that students experience when learning online. As research into this area is still in an early stage of development, it is appropriate that basic groundwork be laid in terms of what is being established. This study attempts to open up a field of enquiry into the following questions:

- What emotions are associated with studying online?

- What are the teaching-learning contexts of these emotions?

- How do they relate to student learning?

- What are the practical implications for teaching and learning online?

The study aimed to explore in qualitative terms the lived experience of students learning online particularly in relation to its emotional dimensions. Various staff within the university offering courses online were contacted and their agreement sought in regard to inviting students from their courses to participate in the study. All contacted staff responded positively and the students enrolled in these courses were sent an email inviting them to participate in the study. Eleven students volunteered to take part and were subsequently interviewed. Bradley [48] recommends that a sample size for qualitative research be considered adequate when 'the responses provide no new or conflicting information'. While each participant's story was singular, by the eleventh interview, their stories had together formed a consistent pattern with general themes and individual variations but no new surprises.

Qualitative research 'seeks understandings of specific situations and communicates that understanding through description' [48]. That description is reported, as much as practicable, through the participants' own voices, although the researcher selects and interprets from what the participants have said. The distortion inherent in this selection and interpretation was countered in this study by both the transcripts of interviews and the subsequent research paper being verified by the participants. They were invited to check that their words and intentions had been faithfully represented and that the chosen extracts spoke truly of their experiences.

The participants were interviewed in person or by phone regarding their experience of studying 
online. They were asked particularly to comment on the emotions they had experienced in specific teaching/learning contexts associated with their online learning and the relevance of these to their learning. The interviews were around an hour in length and the interviewer identified particular aspects of the online learning experience and asked the students to reflect on these as well as assessing the experience overall. The aspects included such processes as logging on, following instructions, and accessing resources. The participants were also provided with a checklist of named emotions which the interviewer referred to in the latter part of the interview. This was used as a prompt to further identify the emotions associated with particular learning experiences.

The interviews were recorded and transcribed and the transcriptions analyzed with a view to identifying the emotions reported and the contexts and consequences of those. All the participants spoke of a range of emotions both positive and negative which had been associated with, and had impacted on, their learning. Those which occurred most frequently in the interviews are discussed below. In each case the emotion was named by the participant spontaneously, in response to a probing statement or question by the interviewer (That must have been very frustrating for you), or by referral to the checklist (Can you tell me about any situations where you experienced any of the emotions on the list?).

The chosen pseudonyms and demographic and general backgrounds of the participants are as follows:

\section{Andrew}

Mature age (over 21), postgraduate student in occupational therapy, studying in distance mode, living in a country town, rates himself as experienced with using computers and the internet (using email, taking part in discussion groups, word processing, using other applications), studying the course totally online.

\section{Betty}

Mature age, undergraduate student in social science, studying in distance mode, living in the metropolitan area, rates herself as experienced in using computers and the internet, studying the course totally online.

\section{Catherine}

Mature age, undergraduate student in communication, studying on campus, living in the metropolitan area, rates herself as very experienced in using computers and the internet, studying the course totally online.

\section{Douglas}

Mature age, postgraduate student in occupational therapy, studying in distance mode, living in New Zealand, rates himself as experienced in using computers and the internet, studying the course totally online.

\section{Elizabeth}

Mature age, postgraduate student in occupational therapy, studying in distance mode, living interstate, rates herself as experienced in using computers and the internet, studying the course totally online.

\section{Fleck}

Mature age student with a physical disability, studying library and information management partly on campus and partly in distance mode, living in the metropolitan area, rates himself as very experienced in using computers and the internet, course totally online. 
Joan

School leaver, undergraduate student in social work, studying on campus, living in the metropolitan area, rates herself as moderately experienced in using computers and the internet, studying the whole course online.

\section{Kate}

School leaver, undergraduate student in marketing and communication, living in a country town, studying partly on campus and partly in distance mode, rates herself as very experienced in using computers and the internet except in the use of discussion forums, studying the whole of one course and part of another online.

\section{Mona}

School leaver, undergraduate student in journalism, living in the metropolitan area, rates herself as very experienced in using computers and the internet, studying the course totally online.

\section{Polly}

Mature age postgraduate student in professional communication, living interstate, rates herself as experienced in using computers and the internet except for using discussion lists, studying the course totally online.

\section{Sarah}

School leaver, undergraduate student in communication, living in the metropolitan area, studying on campus, rates herself as experienced in using computers and the internet, studying the course totally online.

An (unattributed) but typical quote from the interview transcripts has been included as part of the relevant headings and excerpts from the transcripts are included in italics in the text.

\section{A. Frustration-Well, that's the university for you}

Frustration appeared as the most pervasive emotion associated with studying online. All of the students interviewed had experienced frustration of one kind or another with one aspect or another of studying online. Sometimes, as with Betty, working full time at a demanding job and trying to fit study into the nooks and crannies of life, it was all the little impediments that added cumulatively to a growing frustration. I find that I'm continually frustrated with minor things. Because at the end of a hard day's work I've then got to sit down and study or look things up. And I'd like to be able to just sit down and have it flow, because I'm probably short on patience by that time. For Andrew, working fulltime at two different country centers and studying part time, it was the technology, the unreliability of the internet connection, which was the source of his frustration. Although, unlike Betty, Andrew accepted this frustration as a necessary and manageable aspect of studying online. I guess it's somewhat frustrating when the computer crashes. But that's just part and parcel of using the medium. You just get used to that. And if you can't log on, you just attempt it another time. With Mona it was more the unreliability of the web itself, although her philosophical attitude was similar to Andrew's. Following links...can be frustrating because the links don't work...I basically just leave it if it's not working...I come to the conclusion that there's nothing really I can do about that. For Douglas, it was the university system that let him down. I had my user name, but I still couldn't get any access to [the discussion list]. ...I thought I had all the information, but obviously there was something wrong with the system at their end. 
For some the frustration was associated with a lack of clear instructions for locating the required site or the convoluted process needed to do that. Catherine was one. I don't believe I was given a web page or a web site to look for... I don't think there was any special mention made as to where I was meant to log on. As was Elizabeth: I use the net all the time, but this thing...! I couldn't navigate. I couldn't get in...I spent quite a lot of time wondering, do I really want to do this? And Fleck:. Well after the first week I had heard nothing. Absolutely nothing. I had an email from [the lecturer] saying that the information would be available online, on the web page, with no reference to where the web page was. And Joan: It was really difficult to find the page. It took me about four months before I actually found the resource. The tutor didn't really explain to us what we were supposed to be looking for and what the link actually was. Polly too experienced frustration navigating the system and finding how to get to where she was supposed to be: Logging on was really difficult because I didn't know what my password was, and until you have a password you can't get in to ask someone for help. And when she did get in her problems were far from over. I thought that I was somewhere and I was somewhere else often... And that common problem of people who know what's going on think it's easy. And so the email was: Aw, you just go there and you do this and then that. And vroom, it's done. And I went there and did all the things that were followed and it didn't work...The instructions were very simple, but the application of them seemed quite difficult.

For some, there was frustration associated with the nature or structure of the online material. One of these was Polly again. The way the web pages were set up I found somewhat bewildering...the different pages had very similar layout and it took me quite a while to figure out where I was within the site and so where I was with the instructions. And Mona: For one question I think I spent four hours online trying to track down responses and I couldn't find them. Sarah realized that her frustration was associated with a feeling of being lost in cyber space. She needed to have a sense of where she was in relation to the overall structure of the course, or at least the part of it she was currently dealing with. And the online environment did not provide her with that. I basically had to print out the whole web page, because my learning is more physical, one after the other...I don't know if you know what I mean, but there was no progression of reading it and thinking OK, I've got that. And now I'll go here and I've got that. Whereas when I printed it, I had them in a folder style. Read it. Yep, I understand all that. Next page. Read it. Yep. And that's really the only time I started understanding.

There is also frustration with material being out of date. Betty. A lot of information is still there from last year and I had also printed off all the course information and the weekly exercises before I realized that it was actually still 2001. And Fleck: I just kept getting told by everyone to go see the web site. And it wasn't until the course coordinator tried to do things that she found out that yes, the information's too old.

Elizabeth, Douglas and Polly, all leading busy lives and all studying at postgraduate level, externally from interstate or overseas, felt frustration at the rambling or superficial nature of unmoderated online discussion. Elizabeth. If you don't have really strong adjudication or facilitation, if you don't have a really strong lead in that, then you end up with, I think, a whole group of people who really don't have any better understanding of the issues than you do, all offering opinions and there doesn't really seem to be very much comes out of that. Polly. There were three main concerns I had. One was the difficulty with students articulating ideas for the first time. And they flounder around... and it may not make sense to anybody else. Another thing was a sort of group therapy session which I found frustrating. This is supposed to be an academic learning environment, not a chance for us all to have a big group hug. And a third thing was frustration with some people's absolute stupidity. Good Lord! And for Douglas: The thing I find frustrating is that it doesn't feel like a discussion because it takes so long to get a response from other people...I think it kind of lacks some of the depth you'd get if you were in a face to face situation... The other thing I find frustrating with the online discussion is that there isn't much input from the lecturers...I think it would be useful to have some input from the lecturer to kind of summarize what we've been saying or to point us in another direction or get us to 
explore things in more detail.

There was a general desire to get things done quickly with a minimum expenditure of unnecessary time, and frustration associated with that desire being thwarted. Joan: Frustration, yes, definitely, with all the time that it takes. It just took so long to find [the discussion list]. I found it once and never went back there. Catherine. [Accessing the data base] was slow and that in itself is very frustrating when you've got timelines.

For Sarah and Douglas it was the overall experience of studying online. Douglas felt frustrated by the isolation and lack of connection that online study represented. What I found quite hard and frustrating is that I probably would have got more out of being in a room with people exploring ideas...I don't know what they look like. I don't know where they live. I don't know, yeah, who they really are. Sarah just felt uncomfortable with the whole online experience. I just think I shouldn't have done this subject, because being on computers frustrates me anyway.

Frustration was an emotion experienced by all the students interviewed. For some, this was a relatively minor aspect of learning online, whereas for others it caused them to question whether or not they wanted to continue. Much of the frustration was associated with the technology, whether it was working, and how difficult it was to access and navigate. Some was associated with the associated administrative processes, with instructions that were unclear and obscure. Other frustrations were with the design, structure and relevance of the web site content and with the learning processes, especially discussion groups. For some, it was a more global frustration with the total experience of learning online.

\section{B. Fear, anxiety, apprehension-every single day}

Many of the students experienced one or all of the fear, anxiety, and apprehension cluster of emotions associated with their online learning. There was anxiety involved with delays in the system. This was the case for Betty. Because I'm working fulltime and I have to arrange my time very carefully... it caused quite a high level of anxiety, because it was the first week and we were due to have assignments in by the Friday and I couldn't get in. And for Fleck: Three weeks in and I hadn't started...I was getting behind before I even started. There was anxiety too with not knowing just what to do and about finding out what to do. Elizabeth felt this particularly when she was studying overseas. It was 10-14 days sometimes before I got a response about anything and I was really starting to panic...A couple of times I had questions about a paper that was due and [the lecturer] didn't email me back until after the due date had passed... It caused a lot more stress and anxiety than was really necessary. For Betty, it was also trying to work out online how to negotiate the new library system. I had to take time off work, go into the library, sit down with someone and say what's going on? They ran through it all. I don't think I've mastered it. It's still a fearful unknown next time I have to go into the library. There was anxiety for some with trusting the system to deliver assignments electronically. Elizabeth: I don't know whether it's got through. I don't know whether the emails got through or whether the person's been able to download it. Initially too for Mona: I was a little apprehensive at the start because you wonder if it's going to go through... Will something occur in the transmission process?

The prospect of the public exposure associated with aspects of learning online caused anxiety for some students; exposure to an unknown or maybe even non-existent audience. Catherine, for example, was required to post assignment answers on a web page. I like to know. I like to know who's reading my work. Is it being read? Because then, why am I doing it? I mean, what's the point? Elizabeth was in a similar situation. Whatever you post is there for the semester. You know, people have access to it on an ongoing basis, whereas if you're sitting in a tutorial room and talking to people, then it's more ephemeral. I think that people take fewer risks in what they say and what they're prepared to talk about. 
For Polly the anxiety was one of general internet anxiety which did not diminish as she became more familiar with the online environment. When asked if the experience of studying online reduced her initial anxiety, she replied: No. Perhaps it was heightened...I was reaffirmed in my belief of my being internet-challenged by not being able to follow simple instructions.

Although Mona acknowledged the significance of anxiety in relation to learning, she thought that this was less a concern with learning online than in a face to face situation. I've found that I've probably been more willing, not been more objective, but more willing to_express my true feelings about something online... If you don't know the answer in a class quiz you do become quite anxious... Online you've got the time and you think OK, I'm going to go out and get these answers.

The peculiar nature of the electronic environment was a source of anxiety for most of the participants. For some it was anxiety associated with a lack of control over the processes of the system. Work or ideas were submitted and then dealt with (or not) in some mysterious and invisible way over which the student could have no influence. The public and relatively permanent nature of online communication was also a source of fear and anxiety as was the impersonal and largely anonymous nature of that communication. Demonstrating the principle that what appears to be the same experience may engender different emotional responses in different people [20,16], the relative lack of anxiety of the online environment, with more time and space being available, was also identified as a factor.

\section{Shame/embarrassment—surely a three year old could maneuver through this}

Students experienced shame and embarrassment associated with the sense of feeling exposed and with feeling incompetent at tasks they felt they should be able to complete. Catherine was one of them. There were times when I was embarrassed because my work was there to see...You don't even know who they are and they're critiquing your work. As was Elizabeth: Perhaps there's some fear or some sense of exposure or potential shame about putting something up there that's going to be there for the world to see for a long period of time. You might give yourself freer rein in a less public situation. And Polly: And there's some sort of feeling like a dork. I suppose that's shame and embarrassment. And Mona: Embarrassment when you find that you've posted something on the net and you've misspelled it. And you look at it and go Aw no! I've got that there for everyone to see. I'm caught out! Kate was so embarrassed at being so far behind that she held back from participating: I don't really use the discussion list because I'd look stupid. So I don't use it.

Around half of the participants, interestingly all of them female, spoke of the shame and embarrassment they experienced with having their inadequacies exposed, or potentially exposed, online. Shame has been identified as a significant factor in learning, being associated with a reduced disposition to learn $[49,50]$. And the experiences of students, especially female students, in this study, suggest that the emotions of shame and embarrassment have particular significance in the online environment.

\section{Enthusiasm /excitement-My goodness, this is fantastic!}

For some of the students, learning online was associated with feelings of excitement, even if, like Kate, this were not sustained. When I first started I was all excited about it. I thought: It's going to be great. Rah! Rah! But then at times I think, Cor, it's hard. For Joan, it was the thrill of actually being online: A bit of excitement the first year that I came and discovered I had my own email address and could print out lecture notes and things like that. It was quite exciting that we were so technologically advanced...It was good that I could go and log on to a computer and I could surf the net there and 
that would be fine. For Mona and Andrew there was excitement associated with experiencing a new way of learning. Mona: Excited as well, because it was a new tool of learning I guess. Which I like. It offered the opportunity to become familiar with another method, which was pretty good. Andrew: There is a sense of excitement... this journey that I'm back on again now, and I'm very happy to be on, is a lot easier for me to manage [than previous study]. So, technology has made it a lot easier to juggle.

For Andrew there were other aspects of learning online that also engendered enthusiasm and excitement. One of these was the actual content of the course, which he found related strongly to his professional and personal life. It's been more around that personal reflection and that personal understanding and putting things into my own terms. He was also excited by the experience, while living in a remote country town, of connecting with others embarked on a similar professional journey. That potential to be connecting with people around the country and one overseas...the use of technology... in enabling this sharing of information and this connection with people.

Catherine expressed some irony when speaking of her excitement with studying online. It was occasioned by a brief comment from the lecturer in response to an assignment she had submitted. $I$ was excited when the lecturer actually did say something. When we got our results, he actually posts our results to our email address. And that was exciting because you got two lines that said Good on you, you got a Distinction or whatever it was. While Sarah acknowledged that excitement played an important part in her learning, she felt that this dimension had been seriously lacking in her experience of learning online. I feel that the way I learn is a lot more, well, what we talk about is a lot more relevant if you're in a big group in a tutorial having a discussion. I think. And that gets me excited. It gets me into the subject. Whereas this has been, I feel like it's a chore, this subject. And I've never felt like that. I've been at uni for three years and I've never felt like that with another subject. Because there's no engagement. Elizabeth's excitement, too, was less related to the course itself than to the online resources she accessed along the way. I've used lots of things that are in other commercial sites...through WHO, lots of government sites around the place...It's certainly exciting...I'm getting lots of good information from them...I'm not sure how much directly relates to the study I'm doing.

Not all the emotions identified by the participants were negative ones. Enthusiasm and excitement were among the positive emotions seen to play a significant part in the learning experience. There was the excitement associated with learning in a new way, using new technologies. Excitement too with what could be gained from learning online, both in terms of course content and of the connections made possible with other sites and with other people. For some, the excitement associated with learning was significant in its absence from the online context.

\section{E. Pride-I made a good assignment}

A sense of pride in their accomplishments was expressed by a number of the participants, including pride at succeeding in the online environment. As Polly said: I wrote things I was proud of. And also there was pride in managing this environment despite my fears. For Mona: When you know you've done a good piece of work and you put that on the net and you get positive feedback. It makes you feel quite proud. Andrew too derived a sense of pride from the affirming feedback of others. Recognition as a practitioner. That what I say has some meaning or some relevance. That it is a considered sort of response or a considered understanding of different issues.

Pride was identified by Ingleton and O'Regan [50] as a critical emotion in nurturing student learning and in engendering a positive disposition to learn. In the online environment, with its characteristics of publicness and permanence, the potential for pride is very great. 


\section{CONCLUSION}

This paper has examined some of the literature to do with emotion, emotion and cognition, learning online and the relationships between all of these. It has also looked at the lived experience of eleven students who are studying at a university committed to delivering more and more courses online. It has identified emotions those students experienced learning online and the particular contexts in which that experience occurred. From all of this, two kinds of conclusions can be drawn, one practical and one theoretical.

In practical terms, implications can be based on the pragmatic assumption that learning will be enhanced when negative emotions are minimized and positive emotions maximized. From the experience of the students interviewed in this study, this is likely to occur when:

- the technology is reliable, accessible and usable to the point of being invisible in its functioning

- instructions for accessing the required sites are clear, explicit, delivered upfront, and make no unjustified assumptions as to students' knowledge and awareness of online processes

- $\quad$ sites are maintained and kept up to date

- content is designed to make explicit the structure of the material and to facilitate the user's navigation through and awareness of location in that structure

- guidance is provided for appropriate, relevant and constructive participation in discussion groups; responsibility is taken for moderation and facilitation of discussion groups

- posting processes are explicit with students receiving prompt and automatic acknowledgment when postings are received

- processes are put in place for students to have an indication of the actual make up of the audience for any submissions they post online; provision is made for class members to become known to each other as real people with their own idiosyncratic interests and characteristics

- where possible, online communication is augmented with face to face meetings

- a culture of risk-taking is encouraged in which supportive process are put in place for dealing with differences and experimenting with ideas and possibilities

- criteria for excellence are made explicit and the attaining of these criteria is acknowledged explicitly

Both the evidence from the literature and that from the student interviews strongly points to the centrality of emotion to the process of learning, specifically here of learning online. The implication is that any theory of learning which fails to take account of this centrality is lacking a critical element and is, therefore, seriously deficient in its representation of reality. Emotion has been shown to be significant in relation to attention, memory and decision making, all of which are of critical importance in the learning process. Questions that emerge from that include what emotions, what experiences engendering those emotions, determine where and to what extent students focus their attention? Similarly, in what ways and to what ends is emotion involved in what is remembered? What are the implications of that, both for what students remember from any learning situation and for the emotion-related memories they bring from one learning experience to another? What part do what emotions play in the various decisions related to all the learning experiences students encounter when studying online?

This paper focused on emotions and learning and on the relationship between these two phenomena. It also explored the emotional experiences of students learning online. Particular emotions were identified as being significant for those students, including frustration, fear/anxiety, shame/embarrassment, enthusiasm/excitement and pride. The participants in the study reported particular contexts in which those emotions seemed to inhibit or enhance the teaching/learning 
process. The effect of these emotions was variable, depending on the strength and nature of the emotion involved as well as its associated learning context. For some, the emotions experienced and the corresponding engagement with their learning was extreme. Elizabeth, for example had been so emotionally traumatized by her online learning experience that she cried throughout the hour-long telephone interview. She was seriously considering withdrawing from her program. Andrew, at the other end of the emotional spectrum, was motivated by the excitement, enthusiasm and enjoyment associated with his online learning. For the others, there were emotional experiences that contributed positively to their learning as well as those that had detrimental effects, but not overwhelmingly so.

The importance of emotions is being acknowledged in many aspects of human endeavor and emotions are claiming an increasingly respectable place in the theory and research of a diverse range of academic disciplines. It is clear that emotions play a critical role in the teaching/learning process and that this role must be addressed in both the theory and practice of teaching and learning. Exactly what this role is and how it can best be dealt with is an area still requiring much exploration, particularly as new technologies become an integral part of that process.

\section{REFERENCES}

1. Dirkx, J., The power of feelings: Emotion, imagination, and the construction of meaning in adult learning, New Directions for Adult and Continuing Education, Vol.89, pp 63-72, Spring, 2001.

2. Barbalet, J., Emotion, Social Theory and Social Structure, Cambridge University Press, Cambridge, 1998.

3. Frijda, N., Manstead, A. \& Bem, S. The influence of emotions on beliefs. In: Frijda, N., Manstead, A. \& Bem, S., Emotions and Beliefs: How Feelings Influence Thoughts, Cambridge University Press, Cambridge, 1-9, 2000.

4. Ferro, T., The influence of affective processing in education and training, New Directions for Adult and Continuing Education, Vol. 59, pp 25-33, 1995.

5. Martinez, M., Key design considerations for personalized learning on the Web, Educational Technology and Society, Vol. 4, No.1, pp 26-40, 2001.

6. Boud, D., Cohen, R. \& Walker, D., Introduction: Understanding learning from experience. In: Boud, D., Cohen, R. \& Walker, D., Using Experience for Learning, SRHE \& Open University Press, Buckingham, 1-18, 1993.

7. Martin, B. \& Briggs, L., The Affective and Cognitive Domains: Integration for Instruction and Research, Educational Technology Publications, Englewood Cliffs, 1986.

8. Denzin, N., On Understanding Emotion, Jossey-Bass, San Francisco, 1984.

9. Rolls, E., The Brain and Emotion, Oxford University Press, Oxford, 1999.

10. LeDoux, J., The Emotional Brain: The Mysterious Underpinnings of Emotional Life, Phoenix, London, 1999.

11. Hinton, A., Introduction: Developing a biocultural approach to the emotions. In: Hinton, A., Biocultural Approaches to the Emotions, Cambridge University Press, Cambridge, 1-38, 1999.

12. Darwin, C., The Expression of Emotions in Man and Animals, The University of Chicago Press, Chicago, 1872/1965.

13. Frijda, N., Emotions are functional, most of the time, In: Ekman, P., \& Davidson, R. (Eds.), The Nature of Emotion: Fundamental Questions, Oxford University Press, New York/ Oxford, 112$122,1994$.

14. Ekman, P., All emotions are basic time. In: Ekman, P. \& Davidson, R. (Eds.). The Nature of Emotion: Fundamental Questions, Oxford University Press, New York/ Oxford, 15-19, 1994.

15. Evans, P., Motivation and Emotion, Routledge, London \& New York, 1989.

16. Lerner, J. \& Keltner, D., Beyond valence: Toward a model of emotion-specific influences on judgment and choice, Cognition and Emotion, Vol. 14, No. 4, pp 473-503, 2000.

17. James, W., The Principles of Psychology, Encyclopedia Britannica, Chicago, 1891/1952.

18. Shweder, R., 'you're not sick, you're just in love': Emotion as an interpretative system. In: Ekman, P. \& Davidson, R. (Eds.), The Nature of Emotion: Fundamental Questions, Oxford University Press, New York/ Oxford, 32-44, 1994. 
19. Worthman, C., Emotions: You can feel the difference. In: Hinton, A. Biocultural Approaches to the Emotions, Cambridge University Press, Cambridge, 41-74, 1999.

20. Goleman, D., Emotional Intelligence, Bantam Books, New York, 1995.

21. Averill, J., A constructionist view of emotion. In Plutchik, R. \& Kellerman, H. (Eds.), Emotion: Theory, Research and Experience, Vol.1, Theories of Emotion. Academic Press, New York, pp 305-337, 1980.

22. Damasio, A., Descartes's Error: Emotion, Reason, and the Human Brain, Papermac, London, 1996.

23. Bloom, B. (Ed.), Taxonomy of Educational Objectives: The Classification of Educational Goals: Handbook I, Cognitive Domain. Longmans, Green, New York / Toronto, 1956.

24. Krathwohl, D., Bloom, B., \& Masia, B., Taxonomy of educational objectives. Handbook II: Affective Domain. David McKay, New York, 1956.

25. McLeod, D., Research on affect and Mathematics learning in the JRME: 1970 to the present, Journal for Research in Mathematics Education, Vol. 25, No. 6, pp 637-647, 1994

26. Shelton, C., Portraits in emotional awareness. Educational Leadership, pp 330 -32, September, 2000.

27. Postle, G., Putting the heart back into learning. In: Boud, D., Cohen, R. \& Walker, D. (Eds.), Using Experience for Learning, SRHE \& Open University Press, Buckingham, 33-45, 1993.

28. Gardner, H., Frames of Mind: The Theory of Multiple Intelligences, Basic Books, New York, 1983.

29. LaViolette, P., Teaching with feeling in mind, On the Beam, Vol. 6, No. 2, 1986. http://www.etheric.com/LaViolette/Feelingtones.html

30. Palombo Weiss, R., Emotion and learning, Training and Development, Vol. 54, No. 11, pp 4448, 2000.

31. Clore, G. \& Gasper, K., Feeling is believing: Some affective influences on belief. In Frijda, N., Manstead, A. \& Bem, S. (Eds.) Emotions and Beliefs: How Feelings Influence Thoughts, Cambridge University Press, Cambridge, 1-9, 2000.

32. Stock, B., Getting to the heart of performance. Performance Improvement, Vol. 35, No. 8, pp 613, 1996

33. Greenspan, S., The Growth of the Mind and the Endangered Origins of Intelligence, AddisonWesley, Reading, 1997.

34. Brandt, R., On teaching brains to think: A conversation with Robert Sylwester. Educational Leadership, pp 72-75, April, 2000.

35. Sylwester, R., Unconscious emotions, conscious feelings. Educational Leadership, Vol. 58, No. 3, pp 20-24, 2000.

36. Salzberger-Wittenberg, I., Henry, G. \& Osborne, E., The Emotional Experience of Learning and Teaching, Routledge \& Kegan Paul, London, 1983.

37. Boyle, G., Effects on academic learning of manipulating emotional states and motivational dynamics. British Journal of Educational Psychology, Vol 53, pp 347-357, 1983.

38. Symonds, W., Giving it the old online try. Business Week, Issue 3760, 3 December, 2001.

39. Wong, A., Cyberself: Identity, language and stylization on the Internet. In: Gibbs, D. \& Krause, K. (Eds.) Cyberlines: Languages and Cultures of the Internet, James Nicholas, Albert Park, 175206, 2000.

40. Campbell-Gibson, C., The ultimate disorienting dilemma: The online learning community. In: Evans, T. \& Nation, D. (Eds.), Changing University Teaching: Reflections on Creating Educational Technologies, Kogan Page, London, 2000.

41. Russell, T., Technology wars: Winners and losers, Educom Review, Vol 23, No. 2, 1997.

42. Cookson, P., Implications of internet technologies for higher education: North American perspectives, Open Learning, Vol.15, No.1, pp 71-81, 2000. 
43. Kort, B., Reilly, R. \& Picard, R., External representation of learning process and domain knowledge: Affective state as a determinate of its structure and function. Paper presented at the $10^{\text {th }}$ International Conference on Artificial Intelligence in Education, San Antonio, Texas, 2001. http://affect.media.mit.edu/AC research/lc/AI-ED.html

44. Schaller, D., Allison-Bunnell, S., Borun, M. \& Chambers, M., How do you like to learn? Comparing user preferences and visit length of educational web sites. Paper presented at the Museums and the Web Conference, Boston, Massachusetts, 2002. http://www.eduweb.com/likelearn.html

45. Wegerif, R., The social dimension of asynchronous learning networks. Journal of Asynchronous Learning Networks, Vol. 2, No. 1, 1998. http://www.sloan-c.org/publications/jaln/v2n1/v2n1 wegerif.asp

46. Ng, K-C., Using e-mail to foster collaboration in distance education. Open Learning, Vol. 16, No. 2 , pp 191-200, 2001.

47. Hara, N. \& Kling, R., Students' distress with a Web-based distance education course: An ethnographic study of participants' experiences, Center for Social Informatics, Indiana University, Working paper, 2000. http://www.slis.indiana.edu/CSI/wp00-01.html

48. Bradley, J., Methodological issues and practices in qualitative research, The Library Quarterly, Vol. 63, No. 4, pp 431-449.

49. Ingleton, C., Gender and learning: Does emotion make a difference? Higher Education, Vol 30, pp 323-335, 1995.

50. Ingleton, C. \& O'Regan, K., Recounting mathematical experiences: Exploring the development of confidence in mathematics. Paper presented at AARE (Australasian Association for Research in Education) Conference, Adelaide, December 1998.

\section{ABOUT THE AUTHOR}

Kerry O'Regan is Coordinator of Student Development at The University of Adelaide. Prior to taking up that appointment she worked for many years in learning support at the University of South Australia. She is particularly interested in the lived experience of students associated with the various processes of teaching and learning and of the implications these have for teaching at university. She is part of an award-winning team of Learning Advisers who have been acknowledged for their innovation in developing online support for student learning. Address: Learning and Teaching Development Unit, The University of Adelaide, South Australia, Australia 5005, Telephone: +61 883034721 Fax: +61 88303 3553 Email: kerry.oregan@adelaide.edu.au 